\title{
Erratum to: Evaluation of Comprehensive Treatment Models for Individuals with Autism Spectrum Disorders
}

\author{
Samuel L. Odom · Brian A. Boyd · Laura J. Hall · \\ Kara Hume
}

Published online: 16 September 2009

(C) Springer Science+Business Media, LLC 2009

\section{Erratum to: J Autism Dev Disord \\ DOI 10.1007/s10803-009-0825-1}

It should be noted that for six of the 30 CTMs, the information from model developers was obtained through email communication rather than telephone interviews as originally stated in the paper. Also, since publication of this article, information to which we did not have access at the time of the review became available. An article by BakerEriczen et al. (2007), which examined outcomes for the Pivotal Response Treatment (PRT) model, was published shortly after we had concluded collecting articles for our review. If we had access to the article at the time of the review, the rating of the PRT model for Outcome Data would change to 4 and the rating for Quality would change to 2. Also, additional information provided by the Alpine program supports an Operationalization rating of 5 .

\section{Reference}

Baker-Ericzen, M. J., Stahmer, A. C., \& Burns, A. (2007). Child demographics associated with outcomes in a community-based pivotal response training program. Journal of Positive Behavior Interventions, 9, 52-60.
The online version of the original article can be found under doi:10.1007/s10803-009-0825-1.

S. L. Odom $(\bowtie) \cdot$ B. A. Boyd · K. Hume

Frank Porter Graham Child Development Institute, University of

North Carolina at Chapel Hill, CB 8180, 105 Smith Level Road,

Chapel Hill, NC 27599-8180, USA

e-mail: slodom@mail.fpg.unc.edu; slodom@unc.edu

L. J. Hall

Department of Special Education, College of Education,

San Diego State University, 5500 Campanile Dr., San Diego,

CA 92182-1170, USA 